\title{
Prevalence of over and under weight among school children in Mosul
}

\author{
* Zaid M. Yassen, ** Mazin M. Fawzi \\ * Dept. of Com. Med., ** Dept. of Pediatrics, Mosul College of Medicine, University of Mosul.
}

(Ann. Coll. Med. Mosul 2008; 34(1): 1-8).

Received:19 ${ }^{\text {th }}$ Jun 2007; Accepted: $23^{\text {rd }}$ Jan 2008.

\section{ABSTRAT:}

Aim: To evaluate the prevalence of over and under weight in children aged 6-14 years in Mosul city and to observe the important risk factors.

Methods: A cross-sectional study of four governmental primary schools in Mosul city with a total of 2056 child aged 6-14 years were included. Analysis of the data was done by using SPSS and excel computer systems, $\mathrm{X}^{2}$ test was used for statistical analysis.

Results: The study reveals that the prevalence of under weight is $6.8 \%$; on the other hand the prevalence of over weight and obesity were $11.3 \%$ and $9.8 \%$ respectively. Also the study shows that about three quarters of over weight and obese students spend three or more hours daily in watching television, and $(44.2 \%)$ of them eat more than three meals per day.

Conclusions: Overweight and obesity are prevalent problems in Mosul, it is valuable to conduct a study to evaluate the risk factors.

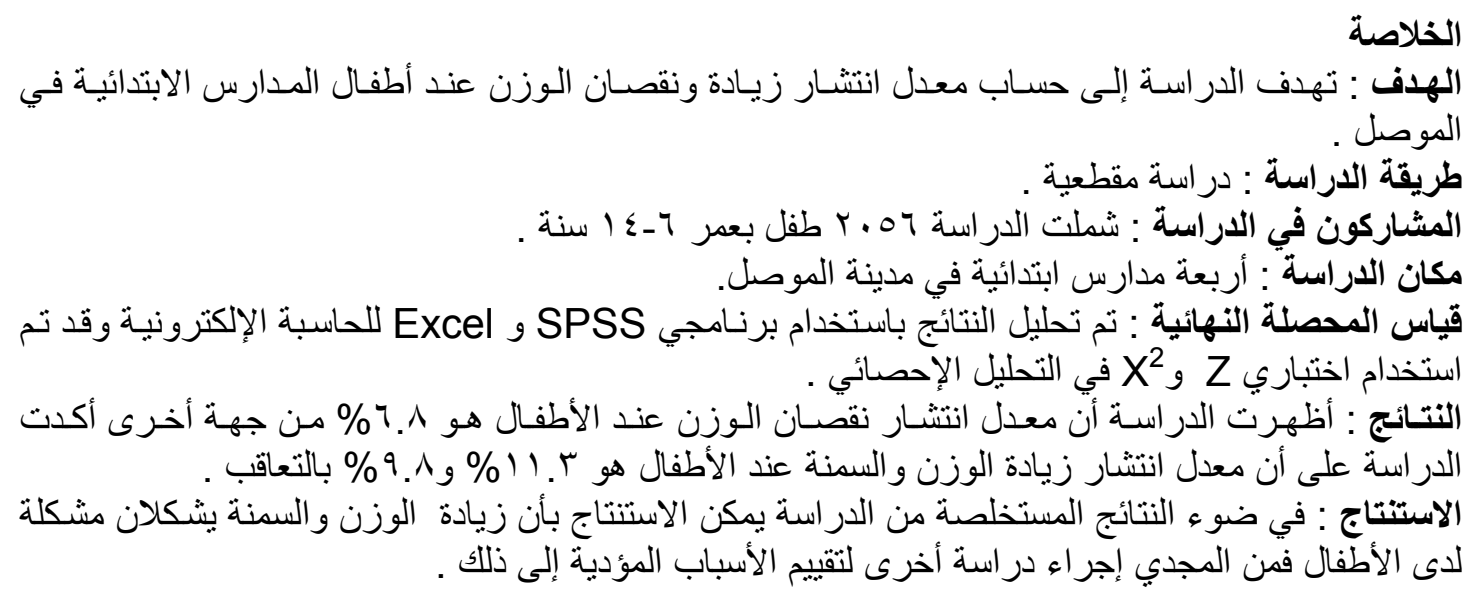


G rowth monitoring is an essential component of pediatric practice. It is conducted mainly through the use of growth charts; their value resides in helping to determine the degree to which physiological needs for growth and development are met during the important childhood period ${ }^{(1)}$.

Primary school aged children may have no routinely scheduled health care visits during this age range, so preventive care and counseling during this time may need to be incorporated into sick visits or conducted through school surveys. This includes assessment of growth and development and screening for any other abnormalities, in addition to reinforcement of healthful behaviors regarding exercise, sleep, and diet $(2,3)$

Obesity is an increasing public health problem in high income countries as well as several low and intermediate income countries $^{(4,5)}$. During the last 30 years the number of overweight children has almost doubled so prevention during childhood is an essential component of the efforts to combat this global problem ${ }^{(6,7)}$. Sedentary life style is a very important factor in increasing the risk of obesity in young adults ${ }^{(8)}$.

Growth monitoring by using different types of growth charts (weight for age, height for age, weight for height, and body mass index for age) is an easily applicable method and should be used by pediatricians, general practitioners, and health workers ${ }^{(3,9)}$.

Body mass index (BMI) is a relative weight measure; it shows the excess in body weight related to excess body fat, and there is a strong curvilinear relation between BMI and relative body fat mass ${ }^{(9-11)}$. It is a standard assessment tool in adult and now there is an international support for its use in children ${ }^{(12,13)}$. The main advantage of $\mathrm{BMI}$ is for the assessment of the risk of diseases mainly those which are obesity related and those associated with malnourishment ${ }^{(11,14)}$.

Body mass index is used differently with children and teens than it is with adults. It is referred to as BMI for age; the most widely used BMI for age charts are those of the centers for disease control and prevention (CDC) ${ }^{(15-18)}$.

The aim of the present study is to measure the point prevalence of under weight, over weight, and obesity among children aged 614 years in Mosul, and to estimate the frequency of factors which are associated with over weight in the study population.

\section{Methods}

The present study was conducted in Mosul over a three months period from the $10^{\text {th }}$ of October 2006 to the $10^{\text {th }}$ of January 2007.

In this study it was decided to include four governmental primary schools in Mosul. The schools were chosen randomly in 4 different districts inside Mosul City after the approval of the Directorate of Education in Mosul.

A total of 2056 pupils aged 6-14 years were interviewed and examined by one of the investigators. This figure constitutes almost all students who were present in the schools at the time of investigator visits. A questionnaire form was filled for each pupil which contained information regarding age, sex, dietary habits, exercise, and watching television. Pupils' height was measured to the nearest $0.5 \mathrm{~cm}$ by using vertical wall 
scale and the pupil stood in erect position without shoes.

On the other hand, body weight was measured to the nearest $0.1 \mathrm{~kg}$ by using electronic scale using light clothes, and substraction of the clothes weight $(0.5-1.5 \mathrm{~kg})$ was done. Body mass index was calculated for all study sample by using the international formula:

$\mathrm{BMI}=$ body wt (in kg)/height ${ }^{2}$ (in meter) $^{(14)}$.

Then the BMI for each pupil is plotted on the standard international BMI for age curves of the CDC center ${ }^{(15)}$.

Classification of the study sample was conducted as in the following ${ }^{(15,17-19)}$ :

1. BMI for age $<5^{\text {th }}$ percentile was considered under weight.

2. BMI for age from $5^{\text {th }}$ percentile to $<85^{\text {th }}$ percentile was classified as normal.

3. BMI for age from $85^{\text {th }}$ percentile to $<95^{\text {th }}$ percentile was classified as over weight.

4. BMI for age above or equal to $95^{\text {th }}$ percentile was classified as obese.

Analysis of the data was conducted by using SPSS and excel computer systems; $X^{2}$ test and $z$ test were used to conduct the statistical analysis.

\section{Results}

During data collection a total of 2056 students (1010 males and 1046 females) aged 6-14 years were interviewed and examined with a $100 \%$ response rate. Male to female ratio was $0.97: 1$.

Figure (1) exhibits the trends of point prevalence of underweight, overweight, and obesity in male and female population according to age. In males the highest prevalence of underweight was in the age group 14 years, while overweight was common among the age group 11 years, similar trend was observed amongst obese. While in female population the highest prevalence's of underweight and overweight was found in the age group 14 years, nevertheless obesity was common among the age group 12 years.

On the other hand, it is evident from Table (1) that the prevalence of under weight in the study population is $6.8 \%$ although it is more prevalent in females than in males $(8 \%$ and $5.5 \%$ respectively) the difference is significant $(p<0.01)$.

Over weight constitutes $11.3 \%$ with nearly similar prevalences in males and females, while obesity is more prevalent in males than in females $(11.8 \%$ and $7.9 \%$ respectively), the difference is of highly significant value $(p<0.002)$ with overall prevalence of $9.8 \%$.

Table (2) shows that about three quarters of overweight and obese pupils (73.6\%) spend three or more hours daily in watching television compared to about one half $(49.3 \%)$ of the normal weight pupils; the difference is very highly significant $(p<0.001)$. Overweight and obese were almost three times more likely watch TV than normal weight pupils (odds ratio $=2.85,95 \%$ $\mathrm{Cl}=1.91-4.24)$.

Table (3) incorporates one of the important dietary habits of study sample. More than forty percent $(44.2 \%)$ of the over weight and obese pupils use to eat more than three meals per day compared to $35.7 \%$ of the normal weight students; the difference is very highly significant $(p=0.001)$, although odds ratio shows no evident risk (odds ratio $=1.42,95 \% \mathrm{Cl}=1.15-1.75$ ). 

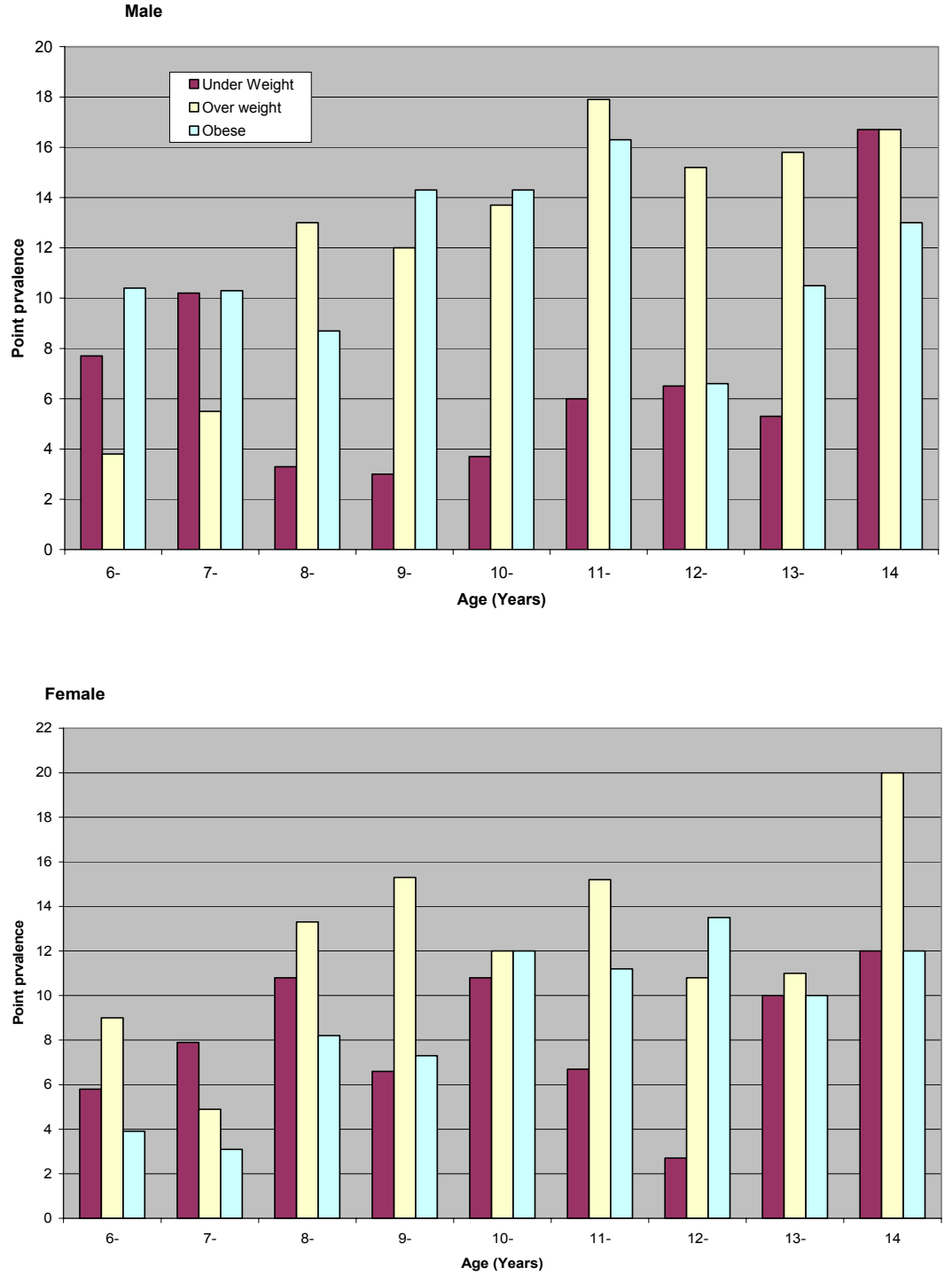

Figure (1) Point prevalence of underweight, overweight, and obesity according to age and gender, Mosul 2007. (NB. Third columns are the obese).

Table (1) Classification of the study population according to BMI for age CDC standards Mosul 2007

\begin{tabular}{|c|c|c|c|c|c|c|}
\hline \multirow{2}{*}{ BMI } & \multicolumn{2}{|c|}{ Male } & \multicolumn{2}{c|}{ Female } & \multicolumn{2}{c|}{ Total } \\
\cline { 2 - 7 } & No. & $\%$ & No. & $\%$ & No. & $\%$ \\
\hline Under weight & 56 & 5.5 & 84 & 8 & 140 & 6.8 \\
\hline Normal & 723 & 71.6 & 758 & 72.5 & 1481 & 72.1 \\
\hline Over weight & 112 & 11.1 & 121 & 11.6 & 233 & 11.3 \\
\hline Obese & 119 & 11.8 & 83 & 7.9 & 202 & 9.8 \\
\hline Total & 1010 & 100 & 1046 & 100 & 2056 & 100 \\
\hline
\end{tabular}


Table (2) Watching TV (hours/day) among study population by gender and BMI for age. Mosul, 2007

\begin{tabular}{|c|c|c|c|c|c|c|}
\hline \multirow{3}{*}{ Gender } & \multicolumn{5}{|c|}{ Normal } & \multicolumn{3}{c|}{ Over weight and obese } \\
\cline { 2 - 7 } & \multicolumn{3}{|c|}{ TV watching } & \multicolumn{3}{c|}{ TV watching } \\
\cline { 2 - 7 } & $<3 \mathrm{hld}$ & $>=3 \mathrm{hld}$ & Total & $<3 \mathrm{hld}$ & $>=3 \mathrm{hld}$ & Total \\
\cline { 2 - 7 } Male & 381 & 342 & 723 & 70 & 161 & 231 \\
& $(61.1)$ & $(48.9)$ & $(100)$ & $(30.3)$ & $(69.7)$ & $(100)$ \\
\hline \multirow{2}{*}{ Female } & 383 & 402 & 785 & 45 & 159 & 204 \\
& $(48.8)$ & $(51.2)$ & $(100)$ & $(22.1)$ & $(77.9)$ & $(100)$ \\
\hline \multirow{2}{*}{ Total } & 764 & 744 & 1508 & 115 & 320 & 435 \\
& $(50.7)$ & $(49.3)$ & $(100)$ & $(26.4)$ & $(73.6)$ & $(100)$ \\
\hline
\end{tabular}

$\mathrm{X}^{2}=26.15 \mathrm{P}<0.001$ d.f. $=1 \quad$ Odds ratio $=2.85$

Table (3) Dietary habits of the study population by gender and BMI for age. Mosul, 2007

\begin{tabular}{|c|c|c|c|c|c|c|}
\hline \multirow{3}{*}{ Gender } & \multicolumn{5}{|c|}{ Normal } & \multicolumn{3}{c|}{ Over weight and obese } \\
\cline { 2 - 7 } & \multicolumn{3}{|c|}{ No. of meals/day } & \multicolumn{3}{c|}{ No. of meals/day } \\
\cline { 2 - 7 } & $\leq 3 \backslash$ day & $>3 \backslash$ day & Total & $\leq 3 \backslash$ day & $>3 \backslash$ day & Total \\
\cline { 2 - 7 } Male & 499 & 224 & 723 & 138 & 93 & 231 \\
& $(69)$ & $(31)$ & $(100)$ & $(59.7)$ & $(40.3)$ & $(100)$ \\
\hline \multirow{2}{*}{ Female } & 471 & 314 & 785 & 105 & 99 & 204 \\
& $(60)$ & $(40)$ & $(100)$ & $(51.5)$ & $(48.5)$ & $(100)$ \\
\hline \multirow{2}{*}{ Total } & 970 & 538 & 1508 & 243 & 192 & 435 \\
& $(64.3)$ & $(35.7)$ & $(100)$ & $(55.8)$ & $(44.2)$ & $(100)$ \\
\hline
\end{tabular}

\section{Discussion:}

Most studies that aimed to determine the prevalence of childhood growth parameters used the cross sectional survey design. In this type of study the exposure and disease are assessed at the same time among a defined population (20${ }^{24)}$. It is considered the best study design for obtaining prevalence of a disease in a population; the main advantage of this design is that it is quick and inexpensive $e^{(25)}$.

Longitudinal studies over the past century have shown growth in height and weight compared to previous generations. Children obesity is now a widespread medical problem in developed and many of the developing countries ${ }^{(26)}$.
Regarding the point prevalence of under weight, a higher figure have been found in another study conducted in Mosul in 2006, the prevalence of underweight was $12.02 \%{ }^{(27)}$. On the other hand, a prevalence of $10.3 \%$ was observed in a study conducted in Baghdad in $2005^{(28)}$. These differences might be due to some variations in the demographic and socioeconomic characteristics of the different study populations or differences in the sample size.

The prevalence of overweight was relatively similar to that reported by other studies conducted in Iraq, such as that carried out in Baghdad in 2005 which showed that the prevalence of overweight was $11.4 \%$ (28) . Furthermore another study conducted in Mosul in 2005 
observed a prevalence of $14.1 \%(20)$. Nevertheless a lower prevalence (6.94\%) has been found in a study conducted in the same setting in $2006^{(27)}$.

Regarding the prevalence of obesity, studies conducted in Egypt and Kuwait observed similar figures to that of the present study ${ }^{(21,29)}$. While two studies conducted in Iraq by Ghazala and Lafta found a lower prevalence of obesity $(4.1 \%$ and $5.12 \%$ respectively) ${ }^{(27,28)}$. A much higher prevalence of overweight and obesity (32.7\%) was observed in $\operatorname{Jordan}^{(24)}$, which might be due to increased used of electronic games and internet in addition to the change in dietary habits, which contributes to increase in body weight.

In the present study TV watching was found to be more prevalent in overweight and obese pupils than in normal weight children. The children are spending a long time in watching TV which leads to inactivity and little energy expenditure and at the same time encourage snacking.

Relatively similar results were observed in the study of Ghazala which was conducted in Mosul in 2006 which showed that about three quarters of obese children spend more than three hours daily in watching $\mathrm{TV}^{(27)}$. A study carried out in USA showed that there was a significant decrease in weight in an intervention group who received a 6 months classroom curriculum to reduce TV use ${ }^{(30)}$.

On the other hand, the prevalence of consumption of more than 3 meals per day was higher in overweight and obese children than normal which is another factor that may lead to caloric overload and might lead to overweight. Similar results have been observed by the study of Ghazala in Mosul in $2006^{(27)}$.

The management should not be limited towards controlling food intake only but needs to be family based and focus on limiting the hours spent in watching TV on one hand and encouraging physical exercise as part of daily routine on the other hand ${ }^{(31)}$. It is highly recommended to disseminate the nutrition education via schools and mass media and encourage children to practice more exercise through an effective systems and programs in the schools.

\section{Conclusions}

From the results of the study, one can conclude that the prevalence of overweight and obesity is considerably high in children age 6-14 years of age in Mosul (11.3\% and 9.8\% respectively). Obesity was found to be more prevalent in males. On the other hand underweight is more prevalent in females. Long duration of TV watching, and consumption of more than 3 meals per day were found to be more frequent in overweight and obese children.

\section{Recommendations}

It is recommended to conduct further studies to determine the exact risk factors for overweight. On the other hand, health education about the important causes and complications of obesity is needed. In addition initiation of school programs to encourage more physical exercise among students is highly recommended. 


\section{References}

1. World health organization. WHO child growth standards methods and development. Geneva, Switzerland: WHO; 2006.

2. Martin S., Mitchells. Blue prints in family medicine, Oxford, Blackwell, third edition, 2003: 31-35.

3. Judith C., Murray L., Peter S. Oxford hand book of clinical specialties, New York, Oxford University Press, $6^{\text {th }}$ edition, 2003: 183-185.

4. Bundred $p$, Kitchiner D, Buchan I. prevalence of overweight and obese children between 1989 and 1998: population based series of cross sectional studies. BMJ,2001;322: 326-328.

5. Tremblay M S, Katzmarzk P T, Willms J D. Temporal trends in overweight and obesity in Canada. International jornal of obesity,2002; 26 :538-543.

6. World Health Organization. Obesity: Preventing and managing the global epidemic, WHO obesity technical report series 894 World Health Organization 2000:Switzerland.

7. Kumanyika $S$, Jeffery $R$ W,Morabia $A$. Public health approaches to the prevention of obesity working group of the international obesity task force. Obesity prevention: The case for action Int $\mathrm{J}$ Obes Relat Metab Disord, 2002;26 : 425-436.

8. Guigliano D, Carnerio EC. Factor associated with obesity in school children. J Pediatr, 2004;80(1): 17-224.

9. Tershakovec AM, Stallings VA. Pediatric Nutrition and Nutritional Disorders, In: Jenson HB, Marcdante KJ, Behrman RE, Kliegman R. Nutrition and Nutritional
Disorders, In Nelson Essentials of Pediatrics, Elsevier, $5^{\text {th }}$ edition, 2005: $57-$ 69.

10. Pi-Sunyer EX et al. Clinical Guidelines on the Identification, Evaluation \& Treatment of Overweight and Obesity in Adults, Obesity Education Initiative, National Institutes of Health Publications, No. 984083, September 1998.

11. Klein S, Romijn JA. Obesity, In: Larsen $\mathrm{PR}$, Kronenberg HM, Melmed $\mathrm{S}$, Polonsky KS. Williams Textbook of Endocrinology, Philadelphia, Saunders Company, $10^{\text {th }}$ edition, 2003: 95-116.

12. Barlow SE, Dietz WH. Obesity evaluation \& treatment: Expert committee recommendations, Pediatrics, 1998; (102)3: 29-39.

13. Dietz WH, Robinson TN. Use of the body mass index as a measure of overweight in children and adolescents. Journal of Pediatrics, 1998; (132): 191-193.

14. Ellis KJ, Treuth M, Wong WW, Abrams SA. Does the body mass index (BMI) adequately screen for obesity in prepubertal children? United States Department of Agriculture-Agricultural Research Service, January 2000.

15. Department of Health and Human Services, centers for Disease Control and Prevention (CDC). BMI is used differently with children than it is with adults, http://www.cdc.gov/nccdphp/dnpa/bmi/chil drens BMI/about childrens BMI.htm.

16. Haslett C, Chilvers ER, Boon NA, Colledge NR. Nutritional Factors in Disease In: Davidson's Principles and Practice of Medicine, London, Churchill 
Livingstone, $19^{\text {th }}$ edition, 2002, Reprinted 2005.

17. American Obesity Association (AOA). Childhood Obesity, February 2005. Available at http://www.obesity.org/subs/childhood/.

18. National Center for Health Statistics in Collaboration with National Center for Chronic Disease Prevention and Health Promotion

(2000).

http://www.cdc.gov/growthcharts.

19. Dept. of Health and Human Services, Centers for Disease Control and Prevention (CDC). BMI is used differently with Children than it is with Adults, http://www.cdc.gov/hccdphp/dupa/bmi/chil drens-BMl/about-childrens-BMI.htm

20. Al-Assaf NH, School-based Student Health Survey- A Pilot in Mosul City (Thesis), University of Mosul, Mosul; 2006.

21. Musaiger $A O$, Overweight and obesity in the Eastern Mediterranean Region: can we control it?, Eastern Mediterranean Health Journal, 2004; (10)6: 789-793.

22. Musaiger AO. Nutritional Problems in the Arab World: Challenges and Perspective, Arab Journal of Food \& Nutrition, 2001; (2)2: 14.

23. Sibai AM, Hwalla N, Adra N, Rahal B, Prevalence and Covariates of Obesity in Lebanon: Findings from the First Epidemiological Study, Obesity Research, 2003; (11): 1353-1361.

24. Ajlouni K, Jaddou H, Batieha A. Obesity in Jordan, International Journal of Obesity and Related Metabolic Disorders. July 1998; (22)7: 624-628.
25. Khachatryan a, Linardakis NM. Biostatistics and epidemiology. McGrawHill digging up the bones series, $1^{\text {st }}$ edition , 2000.

26. Donohoue PA. Obesity, In: Behrman RF, Kliegman RM, Jenson HB. Nelson Textbook of Pediatrics, Philadelphia, Saunders Company, $17^{\text {th }}$ edition, 2004: 58-62.

27. Ghazala YK, Obesity and Over Weight in Children 6-15 years of Age. Board thesis, Iraqi Council for Medical Specializations, Mosul; 2006.

28. Lafta RK, Al Saffar AJ, EisaSA, Hayyawi $\mathrm{AH}$, Abdulhameed FN. Obesity in children: asample from Baghdad. Qatar Medical Journal, 2007; June (16) 1: 10-15.

29. Al-Sahen F. Nutrition Status of Youth (1019 years) in Egypt, Arab Journal of Food \& Nutrition, 2001; (2)2: 22.

30. Thomso R. reducing children's television viewing to prevent obesity, a randomized trial .JAMA, 1999;282: 1561-1567.

31. Krepcio D,Faoll K, Folto SC, Hardesty IT, Golberg JP. Obesity and the school age child. Nursing spectrum, New York Metro Edition, 2004; Feb (9):22-23. 